\title{
COEXISTENCE OF SARCOIDOSIS AND SYSTEMIC SCLEROSIS: A CASE REPORT
}

Thais de Campos Ferreira Pinto",*, Vanessa Félix Nascimento Coelho', Maria Veronica Russo Macchi', Lucas Eduardo Pedri', José Alexandre Mendonça', Rubens Bonfiglioli ', Nadia Regina Bossolan Schincariol', Vanessa Ramos Guissa', Claudia Valeria Vierhout ${ }^{1}$, José Roberto Provenza ${ }^{1}$, André Marun Lyrio ${ }^{1}$

1.Pontifícia Universidade Católica, Campinas (SP), Brazil.

*Corresponding author: thais.fmt@hotmail.com

\section{BACKGROUND}

Sarcoidosis is a granulomatous disease of unknown etiology that characteristically involves the lungs, but also may involve multiple organs. It can coexist with connective tissue diseases, such as systemic erythematosus lupus, Sjögren's syndrome and rheumatoid arthritis, but most of the current literature states that the coexistence with systemic sclerosis is a rare event. On the other hand, the number of case reports has been increased in the past years and it seems to be more frequently than previously suggested.

\section{CASE REPORT}

61-year-old woman complaining about dyspnea during moderate efforts, with no cough, fever, weigh loss or night sweats. Lung computed tomography (CT) was proceeded and found mediastinal adenopathy and micronodules described as possible granulomas. Six months later, she evolved with worsening of the radiographic pattern, this time with ground-grass opacities on pulmonary periphery. Paratracheal lymph node biopsy revealed asteroid bodies and no evidence of tuberculosis or fungal infection, corroborating with the sarcoidosis diagnose. Screening for extrapulmonary manifestations of sarcoidosis was negative. During lung disease investigation, patient also mentioned that she had Raynaud's phenomenon and telangiectasias. Laboratory features was characterized by centromere pattern ANA and positive anticentromere. Therefore, patient also met the criteria for systemic sclerosis sine scleroderma. High doses of corticosteroid $(1 \mathrm{mg} / \mathrm{kg}$ ) and symptomatic treatment for Raynaud's phenomenon were initialized, with significant clinical improvement.

\section{CONCLUSION}

Although rare, the overlapping diagnosis of sarcoidosis and systemic sclerosis is extremely important in clinical practice, since the patient may benefit from the use of corticosteroids - drug of restricted use in isolated systemic sclerosis. 